\title{
BMJ Open Advanced Practice Nursing Competency Assessment Instrument (APNCAI): clinimetric validation
}

\author{
Pedro Sastre-Fullana, ${ }^{1}$ Jose Miguel Morales-Asencio, ${ }^{2}$ Albert Sesé-Abad, ${ }^{3}$ \\ Miquel Bennasar-Veny, ${ }^{4}$ Juan Carlos Fernández-Domínguez, ${ }^{5}$ \\ Joan De Pedro-Gómez ${ }^{4}$
}

To cite: Sastre-Fullana $P$, Morales-Asencio JM, SeséAbad A, et al. Advanced Practice Nursing Competency Assessment Instrument (APNCAI): clinimetric validation. BMJ Open 2017;7: e013659. doi:10.1136/ bmjopen-2016-013659

- Prepublication history for this paper is available online. To view these files please visit the journal online (http://dx.doi.org/10.1136/ bmjopen-2016-013659).

Received 29 July 2016 Revised 16 January 2017 Accepted 17 January 2017

CrossMark

For numbered affiliations see end of article.

Correspondence to Miquel Bennasar-Veny; miquel.bennasar@uib.es

\section{ABSTRACT}

Objective: To describe the development and clinimetric validation of the Advanced Practice Nursing Competency Assessment Instrument (APNCAI) through several evidence sources about reliability and validity in the Spanish context.

Design and setting: APNCAI development was based on a multisequential and systematic process: literature review, instrument content consensus through qualitative Delphi method approach (a panel of 51 Advanced Practice in Nursing -APN- experts was selected) and the clinimetric validation process based on a sample of 600 nurses from the Balearic Islands public healthcare setting.

Methods: An initial step for tool's content development process based on Delphi method approach of expert consensus was implemented. A subsequent phase of tool validation started from the analysis of APN core competencies latent measurement model, including exploratory and confirmatory techniques. Reliability evidence for each latent factor was also obtained. Items' scores were submitted to descriptive analysis, plus univariate and multivariate normality tests.

Results: An eight-factor competency assessment latent model obtained adequate fit, and it was composed by 'Research and Evidence-Based Practice', 'Clinical and Professional Leadership',

'Interprofessional Relationship and Mentoring', 'Professional Autonomy', 'Quality Management', 'Care Management', 'Professional Teaching and Education' and 'Health Promotion'.

Conclusions: Adequate empirical evidence of reliability and validity for APNCAI makes it useful for application in healthcare policy programmes for APN competency assessment in Spain.

\section{INTRODUCTION}

The progressive spread of Advanced Practice Nursing (APN) worldwide ${ }^{1}$ has generated a whole range of approaches in the creation and development of this nurse role, not free of controversy and conceptual ambiguity.
Strengths and limitations of this study

- The Advanced Practice in Nursing (APN) competency assessment instrument resulting of this study relies heavily in well-established APN competency maps from international institutions and it could contribute to support institutional initiatives of APN role delineation and implementation.

- In many settings, no formal APN recognition exist but informal APN roles do, a validated tool for APN-specific competencies assessment capable of identification of those underlying roles could help to further formal APN roles implementation.

- A coherent proposal based on professional APN competencies as shown in this paper could serve for the purpose of creating or revising educational programmes for formal APN role education.

- Limitations of the study are related to the potential self-selection of respondents and lack of evaluation of criteria validity.

Development and establishment of new APN roles is a complex process ${ }^{2}$ that has resulted from a wide variety of reasons, ${ }^{3}$ although a key component is role definition, competency map delineation and role evaluation. ${ }^{4}$

It is noticeable both the heterogeneity of definitions, methodological difficulties through the different attempts at designing competency assessment methods in nursing, ${ }^{5}{ }^{6}$ and the conceptual fragility of many instruments, assessment methods ${ }^{7} 8$ plus the difficulties in defining competence attributes. ${ }^{9}$ Reviews regarding the development of competencies in nursing do exist but none of them is specifically devoted to advanced practice. ${ }^{10-12}$

The progressive worldwide implementation of these advanced roles has led to a growing development of standards of practice and competency maps, ${ }^{13}$ but with many different 
conceptual approaches. ${ }^{14}$ Some recent efforts have been proposed to establish competency frameworks as a background to develop new APN roles ${ }^{15} 16$ or reviewing existing ones, ${ }^{17}$ essentially based on competency mapping and role delineation. ${ }^{18}$ Consequently, this new scenario needs to validate specific tools for APN competency assessment. Nevertheless, in certain cases, existing instruments are restricted to a particular context like the Scandinavian ${ }^{19}$ or the Japanese. ${ }^{20}$ Other instruments address very specific roles, ${ }^{21}{ }^{22}$ or in some cases, these tools offer a more general proposal aimed at inferring competency domains that may be applied to the nursing profession as a whole. ${ }^{23}{ }^{24}$ In the tools analysed, inconsistency in the validation process was detected in order to justify a new instrument development approach.

The aim of this study was to obtain adequate psychometric properties of the scores of an APN-specific competency assessment tool, based on international and multicontextual APN roles and standards of practice in a Spanish nurses' sample: the Advanced Practice Nursing Competency Assessment Instrument (APNCAI). This tool is aimed to operate independently of national/local legislative development, professional practice setting and/or regulatory context.

\section{METHODS}

The development of the APNCAI was based on a multisequential and systematic process initiated with the literature review and subsequential expert consensus approach as pointed before. In order to develop a specific tool for assessing advanced practice competency, the research team started from an exhaustive worldwide literature review that focused on grey literature APN mapping documents, and classical health literature databases (details of this review have been reported elsewhere ${ }^{25}$ ). A final selection of 97 documents from different international settings was made by means of a pure content analysis, assisted by software MAXQDA. Results led to identify 17 core domains (clusters of related competencies) common to APN development at international level. Those initial domains included: Research, Clinical and Professional Leadership, Mentoring and Coaching, Collaboration and Interprofessional Relationships, Expert Clinical Judgement, Ethical and Legal Practice, Education and Teaching, Quality Management and Safety, Consulting, Care Management, Evidence-Based Practice, Professional Autonomy, Health Promotion, Communication, Cultural Competencies, Advocacy and Change Management. This original proposal contained a total of 212 items along the 17 domains. Following, a content validation process based on expert consensus was used in content process. Successive Delphi technique rounds were carried out, and as a result of this phase, 12 competency domains comprising a total of 54 individual competencies emerged, after two rounds of expert consensus plus a post-Delphi depuration approach. The details of this phase have been reported before. ${ }^{26}$
After the prior content validation, a pilot test phase with the initial instrument was conducted over a randomly extracted subsample of 50 nurses from a population of 3400 nurses belonging to the National Health System in Balearic Islands. These nurses belonged to acute care units in different hospitals and primary healthcare centres. All of them were selected if they had more than 15 years of clinical experience. This pilot phase was intended to achieve face validity, understanding of items and usability by cognitive interviews among this random sample of end users. Following this phase, some refinements in the length and clarity of some items were carried out.

\section{Clinimetric tool validation process Design}

A proper reliability and validity content through clinimetric measurement approach ${ }^{27}$ was undertaken using exploratory factor analysis (EFA) and confirmatory factor analysis (CFA) for model generation ${ }^{28}$ to determine the underlying dimensional structure of APN core competencies.

\section{Sample}

Based on the 54 items in the preliminary version of the instrument, a minimum of 600 subjects were required, considering a statistical power of 0.80 and a confidence level of $95 \%$ to identify a difference of 0.03 units in Cronbach's alpha coefficient (hereafter, $\alpha$ ).

Participants were included if they practised either in acute care units in hospital care, long-term care or in primary healthcare centres. No limits in years of experience were set as inclusion criteria to obtain a wide range of professional development situations to be evaluated by the instrument. A final sample of 600 nurses accepted voluntarily to participate from a population of 3400 (18\%). Participants received an electronic password to access the online questionnaire, with guaranteed anonymity in the data processing. Informed consent was also provided.

\section{Data collection}

An online survey approach (Limesurvey) was used to collect data. A mail was sent to all potential participants to present the project, then asking them for voluntary participation and providing access to the final participants to the survey itself. The self-reported tool used a five-point Likert scale ranging from 'never' to 'always'. Participants were asked to answer how often they performed every single competency statement in their current job.

\section{Data analysis}

The items in the preliminary version of the tool were submitted to descriptive analysis plus univariate and multivariate tests of normality. Internal consistency was analysed using Cronbach's $\alpha$ and interitem and itemtotal correlations. Data analysis consisted of a three-step 
sequence in a combination of EFA and CFA approaches. In the first round, principal component analysis (PCA) and a varimax rotation were carried out. Preliminary tests for justifying the analysis using the correlation matrix determinant, the Bartlett's test and the Kaiser-MeyerOlkin (KMO) index were implemented. The Kaiser criterion was applied for extracting factors. Finally, a CFA was applied taking into account well-founded theoretical and empirical reasons, discarding possible capitalisation of random effects from EFA. The overall fit of the model was tested using penalised likelihood ratio $\chi^{2}\left(\chi^{2} / \mathrm{df}\right)$, which is indicative of good fit with values $<3$, the Root Mean Square Error of Approximation (RMSEA) index and its $90 \%$ CIs, taking the value 0.06 as the cut-off for a good fit; the CFI (Comparative Fit Index) with a 0-1 range and the minimum value of a good fit set at 0.95 and, finally, the Standardised Root Mean Square Residual (SRMR), indicating good fit with values $<0.08$. A simple mean imputation method was used to replace missing values $(<5 \%$ of total data). Cronbach's $\alpha$ values for all subscales were also computed. All analyses were performed with the statistical packages SPSS v.22.0 (SPSS., Chicago, Illinois, USA) and LISREL v.9.1 (SSI., Lincolnwood, Illinois, USA).

\section{RESULTS}

The empirical sample was built up of 600 subjects, with a high predominance of women (79\%), $94 \%$ had a university degree in nursing, while $3.8 \%$ had additional degrees in other disciplines. The percentage of nurses with official postgraduate education at master level was $13.3 \%$, and with a doctorate degree $0.8 \%$. For practice environment, hospital-related setting was $69.8 \%$, primary healthcare $16.2 \%$ and other settings were $11.7 \%$. Years of professional experience ranged from $<1$ to 43 , with a mean of 15.4 (SD 10.9), and was normally distributed, as the Kolmogorov-Smirnov test was statistically nonsignificant $(\mathrm{p}=0.10)$. The heterogeneity of the sample of nurses provided a good basis that allowed to minimise the role-centred bias that an APNs-only sample could provide in self-reported scales.

The use of dimensionality reduction techniques requires the existence of an identifiable latent structure, tested by means of the determinant correlation matrix, that was very near to zero $\left(1.5 \times 10^{-17}\right)$, the KMO that obtained an excellent value of 0.96 (values below 0.50 indicate that there is not adequate to reduce dimensions) and the Bartlett's test that was statistically significant $(\mathrm{p}<0.0001)$, indicating that the null hypothesis about the equality between the item correlation matrix and the identity matrix is rejected. The PCA extracted nine significant principal components that explained up to $65.79 \%$ of the variance. The initial factorial structure appeared to be closely related to what was expected from early process stages and in concordance with the key literature, resulting in a nine-factor model with a total of 54 items. In this phase, four items that showed poor performance, below 0.50 loading score, were deleted.

In order to avoid a possible capitalisation of chance of the exploratory factor structure model estimation, a CFA was implemented. The first model tested was exactly the nine-factor model that emerged during exploratory analysis. This nine-factor model showed problems with identification mainly due to the structure of two factors with only three indicators, 'Cultural Competency' and 'Advocacy' as well as factors eight and nine, whose three-item structure generated doubts regarding their fit in relation to the whole scale performance. Error variance of these two factors remained unidentified and, consequently, parameter estimation and the calculation of goodness-of-fit statistics were aborted by the programme. By mixing empirical and theoretical reasoning, these two factors were deleted. To consolidate this approach, all items of the model were revised in order to identify transversal main conceptual elements of advocacy and cultural competence in them if possible. From this approach, the 8 th item of Factor 1, 3rd item of Factor 3, 2nd item of Factor 4, 3rd item of Factor 6 and the 4th item of Factor 8 were identified as containing recognisable elements from both eliminated factors. Also the new model showed that the first factor from the EFA now appeared as two distinct, recognisable independent Factors 1 and 2: 'Research and Evidence-Based Practice' and 'Professional and Clinical Leadership'. Thereby, a new eight-factor latent structure with 44 items was estimated as shown in figure 1.

Labels and items' highest loadings for each factor are given in table 1.

Univariate and multivariate normality tests for all items did not detect special problems of non-normality, and the relative multivariate kurtosis value obtained an adequate value of 1.216. Results showed a good overall fit for the eight-factor model despite a statistically significant $\chi^{2}$ test $\left(\chi^{2}=2275.97, \mathrm{df}=839, \mathrm{p}<0.0001\right)$, but with a penalised likelihood ratio below 3 (2.71), 0.05 for the RMSEA, $90 \%$ CI values of 0.05 to 0.06 , CFI value very near to $1(0.99)$ and finally 0.05 for SRMR, clearly below the cut-off criterion of 0.08 . The factor loadings ranged from 0.50 to 0.87 for each dimension. The CFA loading matrix for the model estimated is shown in table 2.

A full-scale reliability analysis was performed on the 600 subjects' response matrix database for the 44 items in the final version, which attained a reliability estimation of 0.96 using $\alpha$ coefficient. This value indicated a high degree of internal consistency of the full scale. Alpha coefficients for the final eight CFA dimensions were over 0.80. (Research and Evidence-Based Practice 0.92; Clinical and Professional Leadership 0.91; Professional Autonomy 0.90; Interprofessional Relations and Mentoring 0.84; Quality Management 0.84; Care Management 0.88; Professional Teaching and Education 0.81 and Health Promotion 0.85) Taking into account the corrected item-total correlation of each of the 44 items with the corresponding factors, all their correlation values performed over 0.40 (range 0.45 to 0.70 ). 


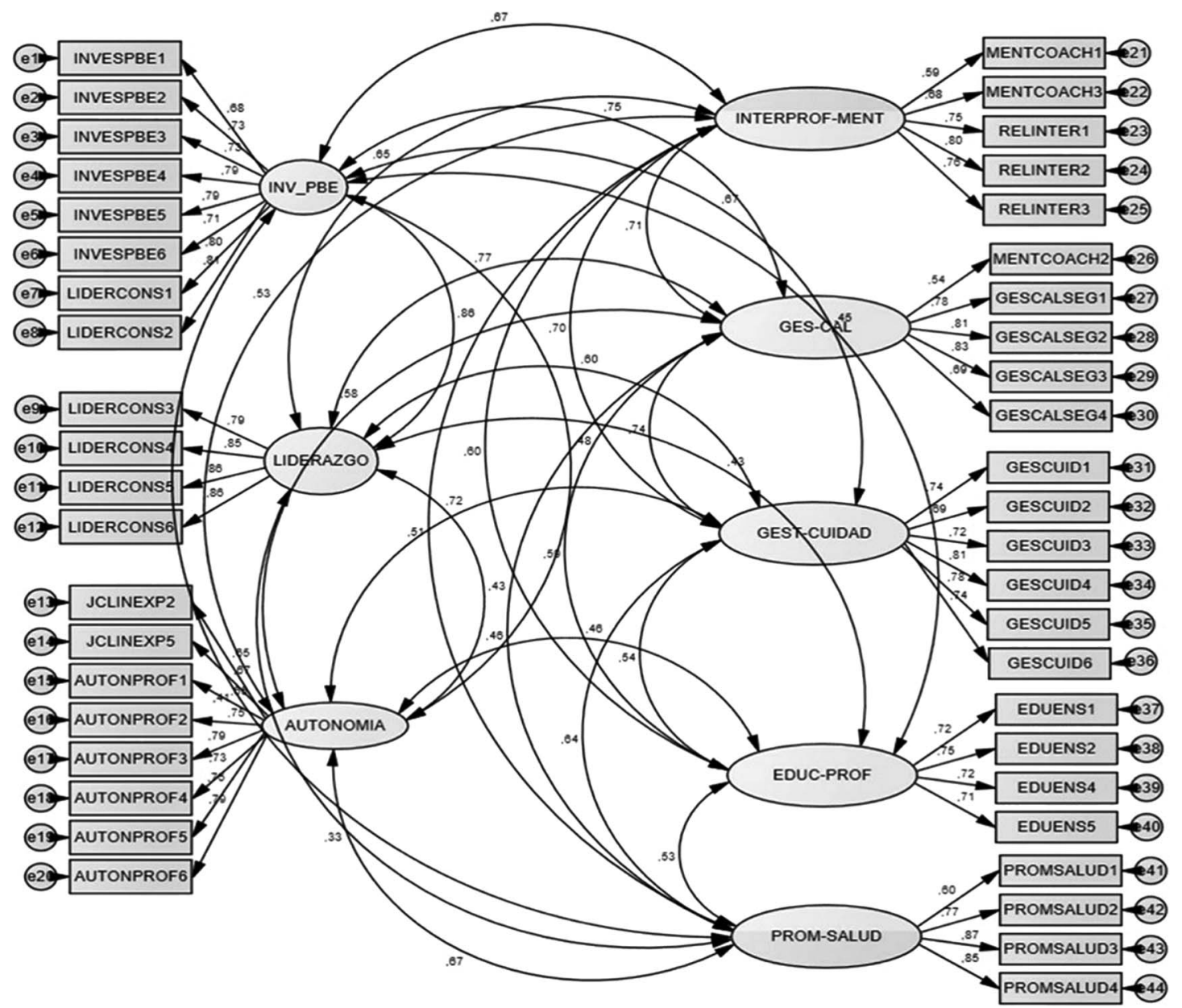

Figure 1 Factorial structure from confirmatory factorial analysis with correlation scores.

Finally, the correlation matrix between latent factors was estimated as shown in table 3. The main findings at this stage are the strongest relationship between Factors 1 and 2. Apart from this, other strong interfactorial relationships appear, as seen below. The second and third strongest relationships appear in the concordance of Factor 5, with a core component of 'Quality Management', and Factors 1 ('Research and EBP') and 2 ('Leadership'). The weakest correlation corresponds to Factors 8 and 2 ('Leadership' and 'Health Promotion', respectively).

\section{DISCUSSION}

APN core competencies have traditionally been an arguable question, ${ }^{29} 30$ with an ongoing discussion about defining the essential competencies for nursing practice and its difficulties for assessment methods and approaches for reflecting real nursing practice in clinical settings.

The aim of this study was to validate an instrument with a deep insight in the competency maps developed for APN roles by internationally competent and recognised institutions and/or organisations, to minimise this issue. Otherwise, recommended CFA was applied in order to evaluate interdependence of responses to the scale proposal. ${ }^{31}$

The main results of this study show how APN competencies cluster around eight competency domains, with a dominant factor based on 'Research and Evidence-Based Practice', followed by 'Inter-Professional Relationship and Mentoring' and 'Care Management', as the top loading factors, in terms of number of items. Likewise, a strong relationship between 'Research and Evidence-Based Practice' and 'Leadership' is shown, which is coherent with the previous literature, which points out a strong relationship between evidence-based practice and leadership in nursing, ${ }^{32}$ that acts as an essential element for evidence-based practice outcome indicators for the APN clinical environment, ${ }^{33}$ but it is essential for the existence of a dedicated source which acknowledge leadership roles, the provision of opportunities to act as a leader, key programmes for leadership development and the presence of specific personal attributes in APNs. ${ }^{34}$

This eight-factor latent structure comprised essential competency dimensions identified previously in literature. The model included elements of research capabilities and clinical leadership roles in conjunction with 
Table 1 Items' highest loading for each factor

\begin{tabular}{|c|c|c|}
\hline Factor & Item & $\begin{array}{l}\text { Factor } \\
\text { Loading }\end{array}$ \\
\hline \multirow[t]{2}{*}{$\begin{array}{l}\text { 1. Research and } \\
\text { evidence-based practice }\end{array}$} & $\begin{array}{l}1.4 \text { "I direct the development of evidence-based plans to achieve the needs of } \\
\text { individuals, families, the community and the population". }\end{array}$ & 0.80 \\
\hline & $\begin{array}{l}1.5 \text { "I use effective strategies to change professional conduct and team work, } \\
\text { thereby promoting the adoption of evidence-based practices and innovations in } \\
\text { the performance of healthcare". }\end{array}$ & 0.80 \\
\hline $\begin{array}{l}\text { 2. Clinical and professional } \\
\text { leadership }\end{array}$ & $\begin{array}{l}2.1 \text { "I assume complex, advanced leadership positions with the purpose of } \\
\text { initiating and channelling the evolution of work". }\end{array}$ & 0.87 \\
\hline 3. Professional autonomy & $\begin{array}{l}\text { 3.1 "I prescribe, implement and supervise pharmacological and } \\
\text { non-pharmacological therapeutic interventions, diagnostic measures, } \\
\text { equipment, procedures and treatments aimed at satisfying the needs of patients, } \\
\text { families and groups, in accordance with the professional preparation, } \\
\text { institutional privileges, local and state laws and professional regulations". }\end{array}$ & 0.78 \\
\hline $\begin{array}{l}\text { 4. Interprofessional relations } \\
\text { and mentoring }\end{array}$ & $\begin{array}{l}\text { 4.1 "I supervise my own professional practice while participating in the } \\
\text { supervision and review of clinical practice at interdisciplinary and } \\
\text { intradisciplinary levels". }\end{array}$ & 0.79 \\
\hline 5. Quality management & $\begin{array}{l}5.3 \text { "I use the results of quality improvement to initiate changes in nursing } \\
\text { practice and the healthcare delivery system". }\end{array}$ & 0.83 \\
\hline 6. Care management & $\begin{array}{l}6.4 \text { "I supervise the results of healthcare programmes and advise on clinical } \\
\text { management and appropriate interventions". }\end{array}$ & 0.84 \\
\hline $\begin{array}{l}\text { 7. Professional teaching and } \\
\text { education }\end{array}$ & 7.3 "I promote and foment an environment that favours effective learning". & 0.81 \\
\hline 8. Health promotion & $\begin{array}{l}8.2 \text { "I provide secondary and tertiary prevention to teenagers and adults with } \\
\text { multiple or chronic health problems". }\end{array}$ & 0.81 \\
\hline
\end{tabular}

nursing practice supervision and assessment, as well as on implementation of patient care programmes, plus other factors dealing with treatments and intervention prescription, complex health problem identification and diagnosis, closely related to the professional autonomy field. Abilities for interprofessional relationship along with capabilities for performing as coach and mentor are other major concepts that fitted coherently in the latent analysis. The other factors fitted to the previous domain-based competency clusters identified in the previous process. Care management-related competencies fitted well in a single factor. Other consistent factors resolved around professional teaching and education.

There is also a consistent correlation between most factors, although all of them are distinct and capable of explaining large proportions of the variance in the data. A noticeable point is the weak correlation between Factors eight and two, with their main component being 'Leadership' and 'Health Promotion', respectively.

Further, there is a recognisable interpersonal relationship component in the competences included. Thus, collaborative practice between APNs and other healthcare providers (especially physicians) and away from previous supervisory relationships, has proved to potentially increase patient access to healthcare, optimise outcomes and improve communication, education and fiscal usage of healthcare facilities. ${ }^{35}$

Transitional care as a component of care management has also shown a key role in APN competencies. This area of professional development has been described in the literature as essential for increasing time to readmission, associated comorbidities or death, reducing readmissions and healthcare costs, while maintaining quality of life and functioning, by providing coordination and continuity of healthcare as patients transfer between different locations. ${ }^{36}$

Moreover, the leadership and knowledge brokering component ${ }^{37}$ understood as APN capabilities for improving evidence-based practice accessibility and consumption in their clinical context of reference, also emerges as an important area of competence ("Research and Evidence-Based Practice" with "Clinical and Professional Leadership" and "Professional Autonomy"), as has been previously reported in different APN areas of practice. ${ }^{38}$

One arguable point in the final eight-factor model proposal is the lack of a domain for 'advocacy', consistently identified as essential to APNs. ${ }^{39}$ The fact is that advocacy is underlying present in many of the other factors obtained and several competencies intrinsically encompass advocacy interventions.

Finally, the latent structure obtained is consistent with the main APN competency maps retrieved from international organisations, and those countries where APN has a consolidated development. ${ }^{40-43}$ Those competency mapping developments for APN closely related to Anglo-Saxon countries show that despite differences in APN role development approaches due to different healthcare system needs response, they share commons traits when working in identifying core APN competencies no matter the specific role described/ 
Table 2 Confirmatory factor analysis (CFA) loading matrix model of 8 factors

\begin{tabular}{lllllllll}
\hline Items & F1 & F2 & F3 & F4 & F5 & F6 & F7 & F8
\end{tabular}

1.1 Acts either as a primary researcher or as a collaborator with other

0.65 health practitioners on the team or in a community context; identifies, leads or supports research that promotes or benefits healthcare.

1.2 Assesses current clinical practice, on an individual and systemic level based on the latest research findings.

1.3 Identifies research priorities in his/her area of professional practice.

1.4 Directs the development of evidence-based plans to achieve the needs of individuals, families, the community and the population.

1.5 Uses effective strategies to change professional conduct and team work, thereby promoting the adoption of evidence-based practices and innovations in the performance of healthcare.

1.6 Implements evidence-based algorithms, clinical guides, protocols and paths of action for the population.

1.7 Develops and implements mechanisms for regular supervision and assessment of policies that influence healthcare services and transforms them into health plans, structures and programmes.

1.8 Leads the promotion of interdisciplinary collaborations in order to implement result-oriented patient care programmes that can meet the clinical needs of patients, families, populations and communities.

2.1 Assumes complex, advanced leadership positions with the purpose of initiating and channelling the evolution of work.

2.2 Contributes to the advancement of nursing practice through the development and implementation of innovations.

2.3 Provides consultancy services on the basis of clinical data, theoretical frameworks and evidence-based practice.

2.4 Makes recommendations based on the consultancy process.

3.1 Prescribes, orders and/or implements pharmacological and nonpharmacological interventions, treatments and procedures as defined in the healthcare plans within the appropriate legislative context.

3.2 Diagnoses complex, unstable health problems by collaborating and consulting with the multidisciplinary healthcare team, as indicated by the context, the specialty and individual knowledge and experience.

3.3 Provides users with the necessary information regarding the effects and potential adverse effects of the therapies prescribed. Also offers information concerning the costs, as well as alternative treatments and procedures, where necessary.

3.4 Obtains data regarding the context and aetiology (including factors that are related and unrelated to the disease) that are necessary in order to formulate differential diagnoses and care plans, and to identify and assess the results.

3.5 Selects, prescribes and supervises pharmacological and non-pharmacological therapeutic interventions, diagnostic measures, equipments, procedures and treatments aimed at satisfying the needs of patients, families and groups, in accordance with the professional preparation, institutional privileges, local and state laws and professional regulations.

3.6 Diagnoses and manages acute and chronic diseases while addressing the patients' responses to their disease process

3.7 Requests, carries out and interprets the results of customary screening and diagnostic tests.

3.8 Plans and develops follow-up visits in an appropriate way in order to monitor patients and assess the health/disease process.

0.80

0.87

0.78

0.78

0.63

4.1 Finds time to address the professional concerns and requests of his/ her colleagues.

4.2 Encourages individuals to share any issue or problem that may affect their personal development and any idea or suggestion related to this, helping them solve their problems in an objective or constructive way. 
Table 2 Continued

Items

interprofessional healthcare focused on patients, relatives and/or communities she/he works with, at an individual, organisational and systemic level.

4.4 Supervises his/her own professional practice while participating in the supervision and review of clinical practice at inter disciplinary and intradisciplinary levels.

4.5 Acts as a link (mediating function) between the different professionals involved in the field of health care

4.6 Tutors health workers, university students and others in acquiring new knowledge and skills to help them in their professional practice.

5.1 Anticipates the variability of clinical practice and acts proactively in F1

F2 F3 F4 the implementation of interventions that ensure quality.

5.2 Designs innovations to bring about changes in clinical practice and improvements in the results of healthcare.

5.3 Uses the results of quality improvement to initiate changes in nursing practice and the healthcare system.

5.4 Assesses other nurses, himself/herself and the system through quality control and management as part of a programme of continuous quality improvement.

6.1 Organises the components of the care plan and coordinates healthcare.

6.2 Keeps up-to-date knowledge of the organisation she/he works for as well as the financing of healthcare systems and the way in which these affect healthcare activity.

6.3 Facilitates continued care and evaluates the status of users when adjusting to their health problems in their own life context.

6.4 Supervises the results of healthcare programmes and advises on clinical management and appropriate interventions.

6.5 Contributes to the development of the global healthcare system and adopts nursing models used in the system to obtain optimal results.

6.6 Promotes the ability of the patients, relatives and/or communities she/he works with to participate in decisions related to the care process and managing their health needs, in accordance with the assessment of preferences of the patients, relatives and/or communities she/he works with and the resources available.

7.1 Assumes responsibility for lifelong learning for his/her own professional development and maintenance of his/her professional competencies.

7.2 Promotes and advocates programmes that support the interdisciplinary education of healthcare.

7.3 Promotes and foments an environment that favours effective learning.

7.4 Uses the information obtained in training activities to improve professional performance.

8.1 Participates in the development and implementation of health promotion programmes.

8.2 Provides secondary and tertiary prevention to teenagers and adults with multiple or chronic health problems.

8.3 Promotes self-care in teenagers and adults within the family and/or support systems and facilitates their participation in healthcare whenever appropriate.

8.4 Acts to empower individuals, groups and communities as regards the adoption of healthy lifestyles and self-care.

implemented/assessed. The work presented in this paper also reflects those similarities even from a wider international perspective that included other countries' APN role delineation approach.

\section{Limitations}

One main limitation of the study derives from the heterogeneity of the nurses' sample that includes nurses with $<5$ years of experience, and others with no formal 
Table 3 Correlation matrix of latent factors

\begin{tabular}{|c|c|c|c|c|c|c|c|c|}
\hline & F 1 & F 2 & F 3 & F 4 & F 5 & F 6 & F 7 & F 8 \\
\hline Research and evidence-based practice & 1 & & & & & & & \\
\hline Clinical and professional leadership & $0.89^{* *}$ & 1 & & & & & & \\
\hline Professional autonomy & $0.52^{\star \star}$ & $0.47^{\star \star}$ & 1 & & & & & \\
\hline Interprofessional relations and mentoring & $0.69^{\star *}$ & $0.66^{\star *}$ & $0.58^{* *}$ & 1 & & & & \\
\hline Quality management & $0.76^{\star \star}$ & $0.78^{\star *}$ & $0.62^{* *}$ & $0.71^{\star \star}$ & 1 & & & \\
\hline Care management & $0.67^{* *}$ & $0.60^{* *}$ & $0.75^{\star *}$ & $0.71^{\star *}$ & $0.73^{\star \star}$ & 1 & & \\
\hline Professional teaching and education & $0.52^{\star \star}$ & $0.56^{\star \star}$ & $0.51^{* *}$ & $0.68^{* *}$ & $0.68^{\star *}$ & $0.58^{\star *}$ & 1 & \\
\hline Health promotion & $0.51^{\star \star}$ & $0.40^{* *}$ & $0.74^{\star *}$ & $0.59^{\star *}$ & $0.52^{\star \star}$ & $0.69^{\star *}$ & $0.53^{\star *}$ & 1 \\
\hline
\end{tabular}

postgraduate degrees. A needed explanation of this limitation is based on conceptualising professional competencies, from the perspective that is understandable that no single competency belongs in exclusivity to the APN context. In fact, the competences evaluated may be present in generalist nurses, but, in different developmental gradients, aspect that can be detected by the scale by having several levels of evaluation of each competence.

In relation to professional competency conceptualisation, is arguably that all nurses, no matter they level of practice, could understand the essentials of every single competency with independence of the level of performance that a nurse could reach within a specific competency. From this perspective, a heterogenic sample of nurses provides a good basis that allows to minimise the role-centred bias that an APNs-only sample could provide in self-reported scales. The main argument here is that what the paper describes is essentially the validation of the latent model's structure, and further criterion and evidence validity is a needed step forward from the actual position.

Others limitations relate to the need to obtain criterion validity evidence and the building of normative scores to complete the psychometric validation process, that is not presented in this paper, and is a priority for future studies. Also, qualitative limitations, especially the potential bias derived from voluntary recruitment of the sample, of the nurse sample have to be taken into account for validation purposes in order to understand the external validity of the tool and its measurement capabilities.

\section{CONCLUSION}

This study provides a valid and reliable tool for the assessment of APN core competencies (APNCAI) that also serves to manage the selection and education of APNs, to develop the APN role in healthcare organisations or to formalise non-recognised advanced practice levels in some settings. Its multicontextual and global approach due to its main components being inferred through a process set in an international transversal cluster of competency related elements, provide the potential to be applied in different healthcare settings.
Moreover, our methodological study contributes to APN clarification, defining eight competency domains related to global APN delineated through a rigorous validation process. The resulting tool obtained could provide national organisations with a cornerstone framework for competency assessment with potential application in healthcare policies for APN role delineation and implementation; in direct clinical practice and management organisational levels through $360^{\circ}$ competency assessment (that implies being assessed by superiors, peers and subordinates); in APN education programmes to assess learning outcomes for students' optimal performance and in APN research field to adequate essential competency areas in order to link them to best patient outcomes.

An international validation process, initially in the European context, is a necessary first step for further development of the tool. Assessment of the discriminant capabilities of the scale is also an interesting line of immediate development, exploring the sensitivity of the tool to identify potential APN roles under not formally structured APN services, or to compare level of competency between similar APN programmes in different healthcare settings. This initial effort has to be followed by an ulterior European first, and posterior international-level validation process, to overcome a full internationally applicable APN competency assessment tool.

\section{Author affiliations}

${ }^{1}$ Balearic Islands Health Service, Palma, Spain

${ }^{2}$ Nursing and Podiatry Department, Universidad de Malaga, Malaga, Spain

${ }^{3}$ Faculty of Psychology, University of Balearic Islands, Palma, Spain

${ }^{4}$ Nursing and Physiotherapy Department, Universitat de les Illes Balears,

Palma, Spain

${ }^{5}$ Evidence, Lifestyles and Health Research Group, Research Institute of Health Sciences, Universitat de les Illes Balears, Palma, Spain

\section{Twitter Follow Miquel Bennasar-Veny @miquelbennasar}

Contributors PS-F, JMM-A and JDP-G participated in the conception and design of the study and drafted the first version of it, as well as the manuscript. MB-V and JCF-D participated in the development of the study and also revised critically the draft of the manuscript. AS-A contributed decisively in the confirmatory factorial analysis part, all with a key intellectual contribution to the final version. All authors read and approved the final manuscript and approved its submission to the journal.

Funding The study was funded by Balearic Islands Nursing Council, Spain. 
Competing interests None declared.

Provenance and peer review Not commissioned; externally peer reviewed.

Ethics approval The study was approved by the ethical committee of the Balearic Islands University

Data sharing statement No additional data are available.

Open Access This is an Open Access article distributed in accordance with the Creative Commons Attribution Non Commercial (CC BY-NC 4.0) license, which permits others to distribute, remix, adapt, build upon this work noncommercially, and license their derivative works on different terms, provided the original work is properly cited and the use is non-commercial. See: http:// creativecommons.org/licenses/by-nc/4.0/

\section{REFERENCES}

1. Schober M, Affara FA. International Council of Nurses: advanced nursing practice. Wiley-Blackwell, 2006.

2. Hutchinson $M$, East L, Stasa $H$, et al. Deriving consensus on the characteristics of advanced practice nursing: meta-summary of more than 2 decades of research. Nurs Res 2014;63:116-28.

3. Delamaire ML, Lafortune G. Nurses in advanced roles: a description and evaluation of experiences in 12 developed countries. OECD Heal Work Pap. OECD, Directorate for Employment, Labour and Social Affairs. 2010, doi:org/10.1787/5kmbrcfms5g7-en

4. Bryant-Lukosius D, Spichiger E, Martin J, et al. Framework for evaluating the impact of advanced practice nursing roles. J Nurs Scholarsh 2016;48:201-9.

5. Dumpe ML, Kanyok N, Hill K. Use of an automated learning management system to validate nursing competencies. J Nurses Prof Dev 2007;23:183-5.

6. Axley L. Competency: a concept analysis. Nursing Forum 2008;43:214-22.

7. Ringerman E, Flint LL, Hughes DE. An innovative education program: the peer competency validator model. J Nurses Staff Dev 2006;22:114-21.

8. Meretoja R, Leino-Kilpi $\mathrm{H}$. Instruments for evaluating nurse competence. J Nurs Adm 2001;31:346-52.

9. Scott Tilley DD. Competency in nursing: a concept analysis. J Contin Educ Nurs 2008;39:58.

10. Kako M, Mitani S. A literature review of disaster nursing competencies in Japanese nursing journals. Collegian 2010;17:161-73.

11. Mildon B, Underwood J. Competencies for home health nursing: a literature review. Community Heal Nurses Canada 2010:7-14.

12. Putra A, Petpichetchian W. Review: public health nurses' roles and competencies in disaster management. Nurse Media J Nurs 2011:1:1-14.

13. Traynor V, Inoue K, Crookes P. Literature review: understanding nursing competence in dementia care. J Clin Nurs 2011;20:1948-60.

14. Duffield C, Gardner G, Chang AM, et al. Advanced nursing practice: a global perspective. Collegian 2009;16:55-62.

15. O'Connell J, Gardner G, Coyer F. Beyond competencies: using a capability framework in developing practice standards for advanced practice nursing. J Adv Nurs 70:2728-35.

16. Micevski V, Korkola L, Sarkissian S, et al. University health network framework for advanced nursing practice: development of a comprehensive conceptual framework describing the multidimensional contributions of advanced practice nurses. Nurs Leadersh (Tor Ont) 2004;17:52-64.

17. Hamric AB, Spross J, Hanson CM. Advanced nursing practice an integrative approach. Elsevier Saunders, 2005.

18. Edwards DF. The synergy model: linking patient needs to nurse competencies. Crit Care Nurse 1999;19:88-90.

19. Nieminen AL, Mannevaara B, Fagerström L. Advanced practice nurses' scope of practice: a qualitative study of advanced clinical competencies. Scand J Caring Sci 2011;25:661-70.

20. Takase M, Teraoka S. Development of the Holistic Nursing Competence Scale. Nurs Health Sci 2011;13:396-403.
21. Scarpa R, Connelly PE. Innovations in performance assessment: a criterion based performance assessment for advanced practice nurses using a synergistic theoretical nursing framework. Nurs Adm Q 2011;35:164-73.

22. Lewandowski W, Adamle K. Substantive areas of clinical nurse specialist practice: a comprehensive review of the literature. Clin Nurse Spec 2009;23:73-90.

23. Meretoja R, Isoaho $\mathrm{H}$, Leino-Kilpi $\mathrm{H}$. Nurse competence scale: development and psychometric testing. J Adv Nurs 2004;47:124-33.

24. Lenburg CB. Competency-based outcomes and performance assessment: the COPA model. Unpublished workshop materials. The University of Memphis, and University of Colorado, Health Science Center, 1998.

25. Sastre-Fullana P, De Pedro-Gómez JE, Bennasar-Veny M, et al. Competency frameworks for advanced practice nursing: a literature review. Int Nurs Rev 2014;61:534-42.

26. Sastre-Fullana P, De Pedro-Gómez JE, Bennasar-Veny M, et al. Consenso sobre competencias para la enfermería de práctica avanzada en España. Enfermería Clínica 2015;25:267-75.

27. Streiner D, Kottner J. Recommendations for reporting the results of studies of instrument and scale development and testing. J Adv Nurs 2014;70:1970-9.

28. Jöreskog K. Testing structural equation models. Sage Focus Ed, 1993:294

29. Dowling M, Beauchesne M, Farrelly F, et al. Advanced practice nursing: a concept analysis. Int J Nurs Pract 2013:19:131-40.

30. Gardner G, Chang AM, Duffield C, et al. Delineating the practice profile of advanced practice nursing: a cross-sectional survey using the modified strong model of advanced practice. J Adv Nurs 2013;69:1931-42.

31. Henly SJ. Use progress in psychometrics to advance nursing science: revisiting factor analysis. Nurs Res 2013;62:147-8.

32. Stetler CB, Ritchie JA, Rycroft-Malone J, et al. Leadership for evidence-based practice: strategic and functional behaviors for institutionalizing EBP. Worldviews Evidence-Based Nurs 2014;11:219-26.

33. Elliott N, Begley C, Kleinpell R, et al. The development of leadership outcome-indicators evaluating the contribution of clinical specialists and advanced practitioners to health care: a secondary analysis. J Adv Nurs 2014;70:1078-93.

34. Higgins A, Begley $\mathrm{C}$, Lalor J, et al. Factors influencing advanced practitioners' ability to enact leadership: a case study within Irish healthcare. J Nurs Manag 2014;22:894-905.

35. AMDAA ad hoc work group. Collaborative and supervisory relationships between attending physicians and advanced practice nurses in long-term care facilities. Geriatr Nurs 2011;32:7-17.

36. Garcia-Mayor S, Morilla-Herrera JC, Cuevas-Fernandez-Gallego M, et al. Description of advanced practice nurses interventions through the nursing interventions classification in different care settings for older people: a qualitative study. Int J Nurs Knowl 2016;27:79-86.

37. Gerrish K, McDonnell A, Nolan M, et al. The role of advanced practice nurses in knowledge brokering as a means of promoting evidence-based practice among clinical nurses. J Adv Nurs 2011;67:2004-14

38. Thompson GN, Estabrooks CA, Degner LF. Clarifying the concepts in knowledge transfer: a literature review. J Adv Nurs 2006;53:691-701.

39. Sheehan A. The value of health care advocacy for nurse practitioners. J Pediatr Heal Care 2010;24:280-2.

40. Thomas A, Crabtree M, Dumas M, et al. Nurse practitioner core competencies. The National Organization of Nurse Practitioner Faculties, 2012

41. National Council for the Professional Development of Nursing and Midwifery. Framework for the establishment of advanced nurse practitioner and advanced midwife practitioner posts. 2007.

42. Nursing Council of New Zealand. Competencies for the nurse practitioner scope of practice. 2012:1-11.

43. Carney M. Regulation of advanced nurse practice: its existence and regulatory dimensions from an international perspective. J Nurs Manag 2015;24:105-14. 